\title{
Contralateral Motor Automatisms in Neocortical Temporal Lobe Epilepsy
}

\author{
Seyed M. Mirsattari, Donald H. Lee, Warren T. Blume
}

\begin{abstract}
Background: The lateralizing value of the motor automatisms is generally doubted in most patients with temporal lobe epilepsy. However, subgroup analysis of the seizures of temporal lobe origin suggests a role for motor automatisms in discriminating seizures of neocortical versus mesial temporal lobe origin. Methods: Video-EEG of a patient with well-defined neocortical temporal lobe epilepsy was reviewed to assess the localizing value of motor automatisms. Results: We report a patient with left upper extremity motor automatisms and clonic movements of the proximal left lower extremity with altered awareness as the sole manifestations of right temporal neocortical seizures. Conclusion: Early onset unilateral motor automatisms without dystonic posturing can localize the seizure origin to the contralateral temporal lobe neocortex.
\end{abstract}

RÉSUMÉ: Automatismes moteurs contralatéraux dans l'épilepsie temporale néocorticale. Introduction: On doute généralement de la valeur des automatismes moteurs pour latéraliser le foyer épileptique dans l'épilepsie temporale. Cependant, l'analyse de sous-groupes de crises d'origine temporale suggère que, dans ce type de crises, les automatismes moteurs sont utiles pour distinguer les crises d'origine néocorticales des crises d'origine mésiales. Méthodes: L'ÉEG-vidéo d'un patient ayant une épilepsie temporale néocorticale bien définie a été révisé pour évaluer la valeur localisatrice des automatismes moteurs. Résultats: Nous rapportons le cas d'un patient ayant des automatismes moteurs du membre supérieur gauche et des mouvements cloniques de la jambe gauche proximale ainsi qu'un état de conscience altéré comme seules manifestations de crises néocorticales temporales droites. Conclusion: Des automatismes unilatéraux à début précoce, sans posture dystonique, peuvent indiquer que le lieu d'origine de la crise est dans le néocortex du lobe temporal contralatéral.

Can. J. Neurol. Sci. 2004; 31: 121-124

Temporal lobe originating seizures may present with ipsilateral motor automatisms and contralateral dystonic posturing. ${ }^{1}$ Limb dystonia may mask an automatism tendency. ${ }^{2}$ Motor automatisms are stereotyped and nonpurposeful ictal involuntary movements of the extremities with poorly understood pathophysiology. Jasper attributed them to activation of specific brain regions rather than simply a "release phenomenon" due to inactivation of higher structures. ${ }^{3}$ Contrary to ictal dystonias, ${ }^{4}$ motor automatisms have generally been regarded less reliable in predicting the side of seizure origin..$^{5-9}$ Several previous studies suggested that they were ipsilateral to the origin of seizures in patients with temporal lobe epilepsy (TLE). ${ }^{2,7,10}$ Isolated contralateral motor automatisms in patients with TLE have not been well studied with respect to the origin of the seizures within the temporal lobes. We report a case with isolated contralateral motor automatisms, review the literature and discuss the possible pathophysiology. We suggest that motor automatisms represent a pattern of seizure spread that may occur independently of dystonic posturing and that isolated early onset unilateral motor automatisms can lateralize the seizure origin to the contralateral neocortical temporal lobe.

\section{CaSe Report}

A 60-year-old right handed man developed stereotyped oncemonthly dyscognitive seizures ${ }^{11}$ at age 41 years. Repetitive nonpurposeful movements of the left upper limb with or without accompanying left lower limb movements occurred during 30-45 second episodes of unresponsiveness. Therapeutic levels of phenytoin, carbamazepine and valproic acid failed to abolish these seizures. Sequential generalized tonic-clonic seizures occurred once with low serum antiepileptic drug levels. No relevant neurological antecedents occurred.

Neurological and neuropsychological examinations were normal.

From the Departments of Clinical Neurological Sciences (SMM, WTB) and Radiology (DHL), University of Western Ontario, London, Ontario, Canada

ReCEIVEd February 7, 2003. ACCEPTED IN FINAL FORM JuLy 10, 2003. Reprint requests to: Warren T. Blume, Epilepsy and Clinical Neurophysiology, Department of Clinical Neurological Sciences, London Health Sciences Centre, 339 Windermere Road, London, Ontario, Canada N6A 5A5 

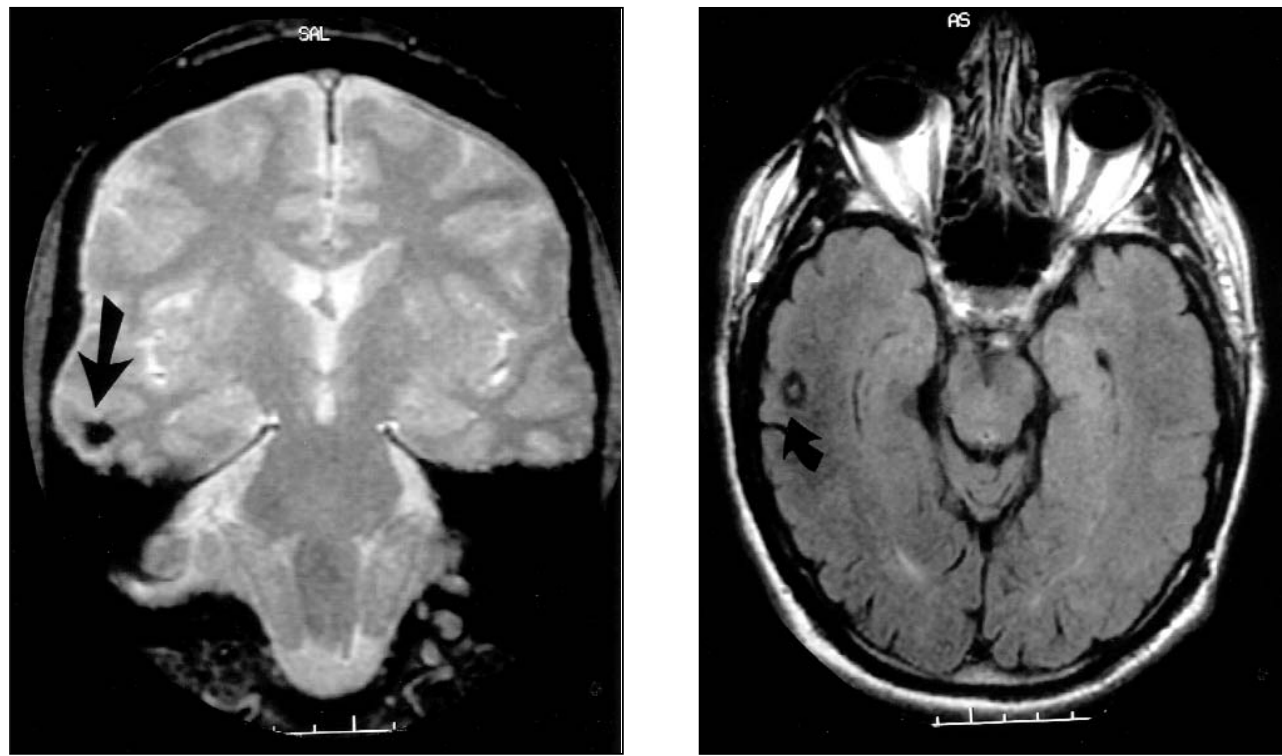

Figure 1: Cranial MRI study: A. Gradient echo coronal image (TR 667/TE20/20 flip angle) shows susceptibility change (arrow) in the right middle temporal gyrus, abutting on the grey matter. $\boldsymbol{B}$. Axial FLAIR shows the lesion (a cavernous angioma) in the right temporal neocortex. Note the normal right hippocampal signal.

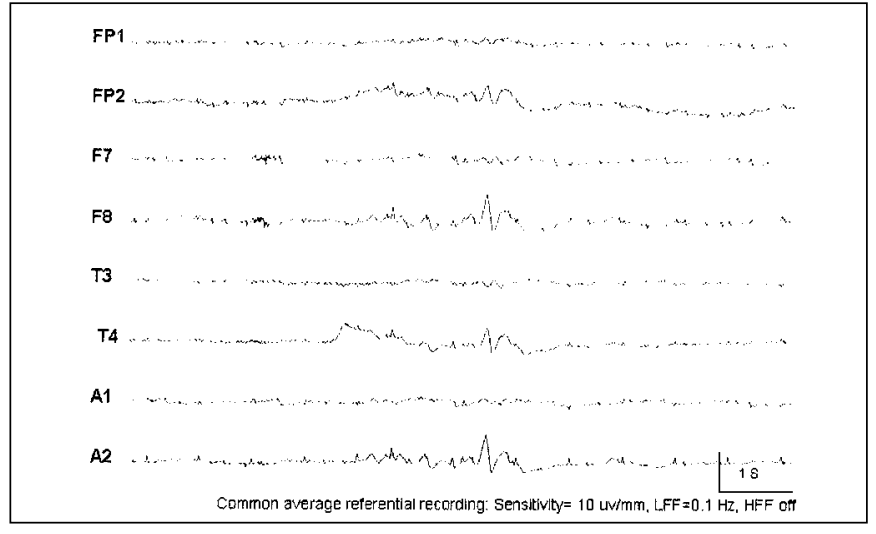

Figure 2: A typical right temporal interictal spike involving $F 8, A 2$, and T4 during sleep.

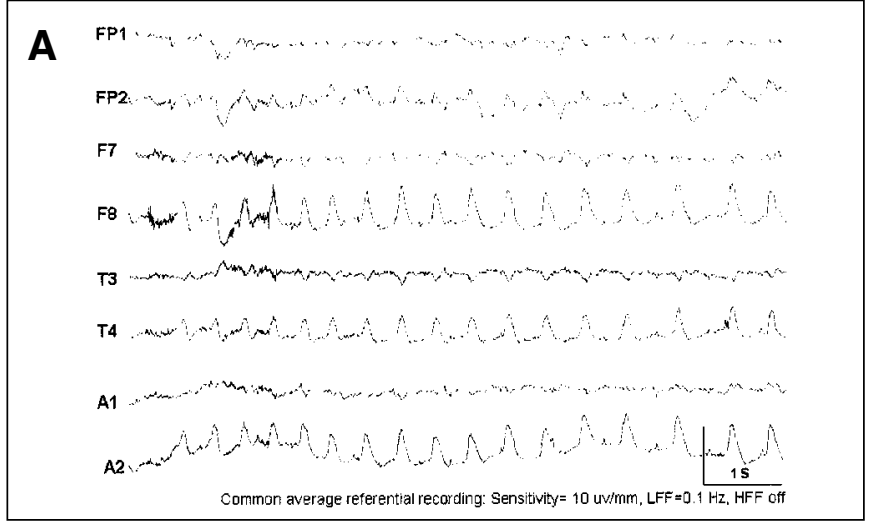

Cranial MRI revealed a $4 \mathrm{~mm}$ lesion with features typical of a cavernous angioma of the right lateral temporal lobe (Figure 1).

Scalp electroencephalography (EEG) revealed infrequent epileptic spikes in the right anterior-mid temporal regions and normal background activity (Figure 2). Video-EEG recorded a typical clinical seizure. He rubbed his left hand against his left thigh using the left fourth and fifth digits while sitting and reading a book held in his left hand two inches above his left thigh. Ictal electrographic changes preceded the clinical seizure by 15 seconds (Figure 3). The same motor automatisms became more intense and repetitive as the electrographic seizure continued. Automatisms were followed by rhythmic clonic movements of the left thigh and then a pill rolling motion of the left thumb as if he was rapidly turning pages of his book. He struggled to keep the book open but momentarily lost control of the pages. Postictally, he resumed reading

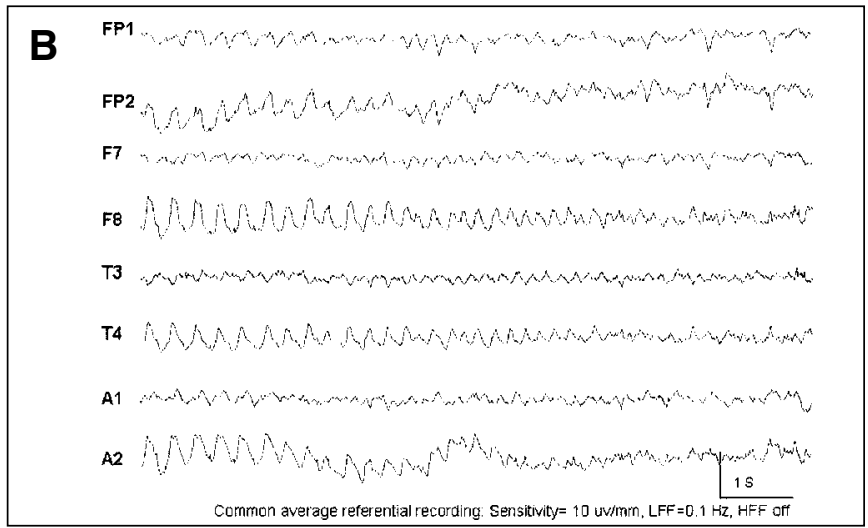

Figure 3: Right hemispheric seizure. A. Onset in the right temporal region $(F 8, A 2, T 4)$ with minimal involvement of the right fronto-polar (FP2) region, then involving entire right hemisphere with spread to left fronto-polar region only (not shown). B. Seizure ends in the right temporal region. 


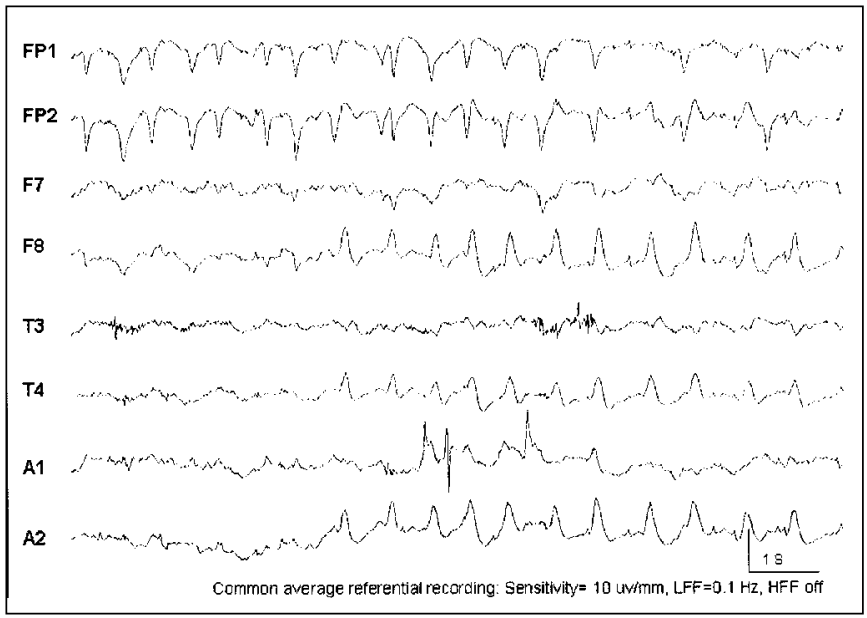

Figure 4: A brief electrographic right temporal seizure involving $F 8$, $A 2, T 4$. Note frequent eye blinks (FP1 and FP2), movement artifact (A1) and muscle artifact (T3).

without apparent deficit. The patient failed to recall the ictus or any aura. Electrographically, the seizure began as high amplitude spikes in the right anterior-mid temoral region with ipsilateral hemispheric generalization in four seconds. The seizure terminated after 65 seconds without postictal changes. Three electrographic seizures were similar except for their duration of less than 12 seconds (Figure 4).

Limited right temporal lobe corticectomy confirmed the lesion as a cavernous angioma. Patient remains seizure free for over two years on carbamazepine monotherapy after the resection of the cavernous angioma.

\section{DiscuSSION}

This case illustrates early onset isolated unilateral motor automatisms without dystonic posturing in a patient with contralateral neocortical temporal lobe seizures. Seizure freedom following surgical resection of the pathologically proven cavernous angioma suggests that the lesion caused his seizures.

Ipsilateral motor automatisms associated with contralateral dystonic posturing during temporal lobe originating seizures have been well-described. ${ }^{1,2}$ Sixteen $(27 \%)$ of 60 patients with TLE had ipsilateral automatisms associated with contralateral dystonic posturing in one study. ${ }^{1}$ Three of their patients, one with mesial TLE and two with neocortical TLE, had contralateral motor automatisms without dystonia. Motor automatisms were exclusively ipsilateral to the side of seizure origin in eight $(30 \%)$ of 27 patients with TLE in another study which did not describe the origin of the seizures within the temporal lobe, neuroimaging findings, or pathology. ${ }^{2}$ Five $(31 \%)$ of 16 with hippocampal and seven $(37 \%)$ of 19 patients with extrahippocampal temporal lobe seizures had "manual" automatisms in one study. ${ }^{12}$ The authors did not report on the bilateral versus unilateral nature of the motor automatisms. One of their patients with hippocampal seizures and five of them with extrahippocampal seizures had motor automatisms without dystonia. Interestingly, one of their patients with extrahippocampal seizures and motor automatisms had cavernous angioma.

The pathophysiology of motor automatisms remains elusive.
Motor automatisms may suggest propagation of temporal lobe originating seizures to the frontal cortex because simple gestures are common in patients with frontal lobe seizures. ${ }^{13}$ Temporal lobe seizures may spread to the mesial frontal cortex, i.e. cingulate gyrus, via the subicular complex and precommissural fornix. ${ }^{14,15}$ Lack of ictal dystonic posturing in our patient presumably reflects ictal sparing of the ipsilateral basal ganglia because anatomical, ${ }^{16}$ electrophysiological, ${ }^{17}$ and single photon emission computed tomography (SPECT) $)^{18}$ studies suggest that direct spread of seizures from the temporal lobe to the ipsilateral basal ganglia is responsible for the contralateral dystonic posturing. Efferent pathways from the amygdala in the stria terminalis project to the caudate nucleus and putamen. ${ }^{19}$

Because of rapid propagation of temporal neocortical seizures to mesial temporal structures, functional studies such as scalp EEG, ${ }^{20-22}$ SPECT, ${ }^{23}$ and interictal $\left[{ }^{18} \mathrm{~F}\right]$ flurodeoxyglucose proton emission tomography $(\mathrm{PET})^{24}$ have generally failed to differentiate neocortical from mesial temporal lobe originating seizures except for a few cases with structural abnormalities of the lateral temporal lobe in which PET was used. ${ }^{25}$ Several studies have used the temporal resolution of the ictal behaviour to identify subgroups of temporal lobe epilepsies. ${ }^{12,26-31}$ Early motor ictal behaviour occurs more commonly in seizures of extrahippocampal temporal origin than in hippocampal attacks. ${ }^{12,31}$

Careful attention to the early ictal semiology may differentiate mesial versus neocortical temporal lobe originating seizures. This case illustrates that motor automatisms represent a pattern of seizure spread that may occur independently of dystonic posturing and neocortical temporal lobe seizures are more likely to present with early onset contralateral motor automatisms without dystonia. Further investigation of a large series of patients, looking specifically for the occurrence of isolated unilateral motor automatisms, would provide definitive evidence regarding the lateralizing and localizing value of this ictal sign.

\section{REFERENCES}

1. Dupont S, Semah F, Boon P, et al. Association of ipsilateral motor automatisms and contralateral dystonic posturing. Arch Neurol 1999; 56:927-932.

2. Chee MWL, Kotagal P, Van Ness PC, et al. Lateralizing signs in intractable partial epilepsy: blinded multiple-observer analysis. Neurology 1993; 43:2519-2525.

3. Jasper HH. Some physiological mechanisms involved in epileptic automatisms. Epilepsia 1964; 5:1-20.

4. Bleasel A, Kotagal P, Kankirawatana P, Rybicki L. Lateralizing value and semiology of ictal limb posturing and version in temporal lobe and extratemporal epilepsy. Epilepsia 1997; $38: 168-174$

5. Kotagal P, Luders $\mathrm{H}$, Morris $\mathrm{HH}$, et al. Dystonic posturing in complex partial seizures of temporal lobe onset: a new lateralizing sign. Neurology 1989; 39:196-201.

6. Berkovic SF, Bladin PF. An electroclinical study of complex partial seizures [abstract]. Epilepsia 1984; 25:668-669.

7. Wada JA. Cerebral lateralization and epileptic manifestations. In: Akimoto H, Kazamatsuri H, Seino M, Ward AA, eds. Advances in Epileptology: XIIIth Epilepsy International Symposium. New York: Raven Press, 1982: 365-372.

8. Marks WJ Jr, Laxer KD. Semiology of temporal lobe seizures: value in lateralizing the seizure focus. Epilepsia 1998; 39:721-726.

9. Serles W, Pataraia E, Bacher J, et al. Clinical seizure lateralization in mesial temporal lobe epilepsy: differences between patients 
with unitemporal and bitemporal interictal spikes. Neurology 1998; 50:742-747.

10. Quesney LF. Clinical and EEG features of complex partial seizures of temporal lobe origin. Epilepsia 1986; 27:S27-S45.

11. Blume WT, Luders HO, Mizrahi E, et al. Glossary of descriptive terminology for ictal semiology: report of the ILAE task force on classification and terminology. Epilepsia 2001; 42:1212-1218.

12. Gil-Nagel A, Risinger MW. Ictal semiology in hippocampal versus extrahippocampal temporal lobe epilepsy. Brain 1997; 120:183192.

13. Geier S, Bancaud J, Talairach J, et al. Automatisms during frontal lobe epileptic seizures. Brain 1976; 99:447-458.

14. Talairach J, Bancaud J, Geier S, et al. The cingulated gyrus and human behavior. Electroencephalogr Clin Neurophysiol 1973; 34:45-52.

15. Rosene DL, Van Hoesen GW. Hippocampal efferents reach widespread areas of the cerebral cortex and amygdala in the rhesus monkey. Science 1977; 198:315-317.

16. Nauta HJW. A simplified perspective on the basal ganglia and their relation to the limbic system. In: Doane BK, Livingston KE, (Eds). The Limbic System: Functional Organization and Clinical Disorders. New York: Raven Press, 1986: 67-77.

17. Yang CR, Mogenson GJ. An electrophysiological study of the neural projections from the hippocampus to the ventral pallidum and the subpallidal areas by way of the nucleus accumbens. Neuroscience 1985; 15:1015-1024.

18. Newton MR, Berkovic SF, Austin MC, et al. Dystonia, clinical lateralization, and regional blood flow changes in temporal lobe seizures. Neurology 1992; 42:371-377.

19. Russchen FT, Bakst I, Amaral DG. The amygdalostriatal projections in the monkey: an anterograde tracing study. Brain Res 1985; 329:241-257.

20. Morris HH, Kanner A, Luders H, et al. Can sharp waves localized at the sphenoidal electrode accurately identify a mesio-temporal epileptogenetic focus? Epilepsia 1989; 30:532-539.
21. Risinger MW, Engel J Jr, Van Ness PC, et al. Ictal localization in temporal lobe seizures with scalp/sphenoidal recordings. Neurology 1989; 39:1288-1293.

22. Ebersole JS, Wade PD. Spike voltage topography identifies two types of frontotemporal epileptic foci. Neurology 1991; 41:14251433.

23. Rowe CC, Berkovic SF, Austin MC, et al. Patterns of postictal cerebral blood flow in temporal lobe epilepsy: quantitative and qualitative analysis. Neurology 1991: 41:1096-1103.

24. Henry TR, Sutherling WW, Engel J Jr, et al. Interictal cerebral metabolism in partial epilepsies of neocortical origin. Epilepsy Res 1991; 10:174-182.

25. Hajek M, Antonini A, Leenders KL, Wieser HG. Mesiobasal versus lateral temporal lobe epilepsy: metabolic differences in the temporal lobe shown by interictal ${ }^{18} \mathrm{~F}-\mathrm{FDG}$ positron emission tomography. Neurology 1993; 43:79-86.

26. Wieser HG. Discussion of 5 typical seizure constellation in the light of neuroanatomy. In: Wieser HG. Electroclinical Features of the Psychomotor Seizure. Stuttgart-London: Gustav FischerButterworths, 1983: 193-208.

27. Walsh GO, Delgado-Escueta AV. Type II complex partial seizures: poor results of anterior temporal lobectomy. Neurology 1984; 34:1-13.

28. Delgado-Escueta AV, Walsh GO. Type I complex partial seizures of hippocampal origin: excellent results of anterior temporal lobectomy. Neurology 1985; 35:143-154.

29. Maldonado HM, Delgado-Escueta AV, Walsh GO, et al. Complex partial seizures of hippocampal and amygdalar origin. Epilepsia 1988; 29:420-433.

30. Kotagal P, Luders HO, Williams G, et al. Psychomotor seizures of temporal lobe onset: analysis of symptom clusters and sequences. Epilepsy Res 1995; 20:49-67.

31. Anand I, Kotagal P, Hammel J, Mascha E. Seizure semiology of lateral versus mesial temporal lobe epilepsy using statistical analysis. Neurology 1997; 48:A240-A241. 